\title{
Research on temporal and spatial variation information of urban land: A case study of Taiyuan City \\ Wen $\mathrm{Yu}^{1,2, a}$, Zhanqiang Chang ${ }^{1,2, \mathrm{~b},{ }^{*}}$, Xiaomeng Liu $^{1,2}$, Wei Wang ${ }^{1,2}$, Jie Zhu $^{1,2}$ \\ ${ }^{1}$ College of Resource, Environment \& Tourism, Capital Normal University, Beijing 100048, China \\ ${ }^{2}$ Key Lab. of 3D Information Acquisition of Education Ministry of China, Beijing 100048, China \\ am15001298698@163.com, bchangkkll@tom.com \\ *Corresponding author
}

Keywords: Land use, temporal and spatial information, Area statistics, Transition matrix, Transformation speed

\begin{abstract}
The temporal and spatial variation information of the land use illustrates a city's development tendency. In this paper, we obtained three land use maps by interpreting and classifying the remote sensing images of different periods in Taiyuan. Then, the area of different land use types was calculated by vector conversion module in ENVI software. Furthermore, we carried out the fusion of attribute information and obtained the corresponding land use conversion matrix by ArcGIS software. Finally, the analysis of land transfer speed and influence factors was conducted by applying the dynamic degree model of land type. The results can provide reliable references to make decisions for the local urban development.
\end{abstract}

\section{Introduction}

The land use is a dynamic process, through which human and nature interact each other. Land is a special resource of human survival. Human activities alter land use patterns and affect environment sustainability. It is therefore very important to learn the land use change and human activities [1]. With the improvement of people's living standards and the level of urbanization, the demand for construction land gains a continuous growth, hence it will reduce the cropland and other types of land to expand the urban area in the future. Whether the land use is reasonable or not has become one of the main factors which restrict people's living level. Only by using land reasonably, consolidating land resources, coordinating the relationship between natural resources and human beings, can the value of land resources be fully utilized, so as to promote the sustainable and efficient development of the national economy [2].

\section{Study area and methods}

\section{Study area.}

Taiyuan City (lat. $37^{\circ} 27^{\prime} \sim 38^{\circ} 25^{\prime} \mathrm{N}$, long. $111^{\circ} 30^{\prime} \sim 113^{\circ} 09^{\prime} \mathrm{E}$, elevation $800 \mathrm{~m}$ above mean sea level), the capital of Shanxi Province, is the famous military base of our north country, culture base and the important heavy industry, energy base. It also boasts the world famous merchants. The Fenhe River, the mother river of Shanxi, covering a total area of 1800 ha, runs through the whole city. The climate in Taiyuan City is very pleasant and charming with a mean annual temperature of about $8^{\circ} \mathrm{C}$, annual rainfall of approximately $450 \mathrm{~mm}$, and annual evaporation of $1,045 \mathrm{~mm}$ during the past ten years $[3,4]$. Just like the other Chinese cities, Taiyuan City has experienced rapid urbanization and economic development. Rapid urban sprawl and a policy of converting farmland to woodlands and grasslands have resulted in complex land use changes that are more obvious in Taiyuan City than in other cities. This makes Taiyuan City an appropriate case study for assessing the changes in land use types. 


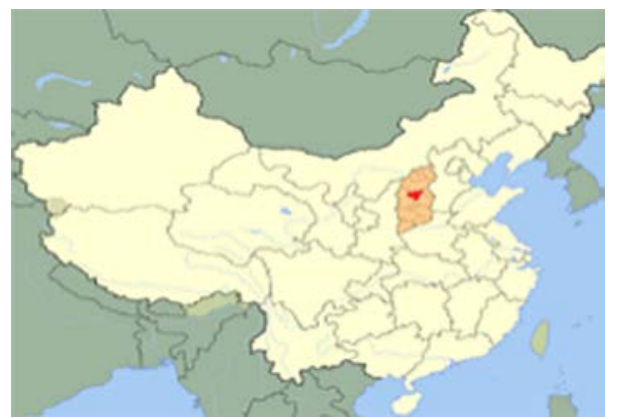

Methods.

Fig.1The geographical location of Taiyuan City

\section{a. The technical route}

In this paper, we obtained land use map by interpreting and classifying the remote sensing images of different periods in Taiyuan, and then gained the land use type areas with the vector conversion by the ENVI. In addition, we carried out the fusion of information with attribute, and then figured out the corresponding land use conversion matrix by the ArcGIS software. Furthermore, the analysis of land transfer speed and influence factors were conducted by applying the dynamic degree model of land type.

\section{b. The processing of the remote sensing images}

1) The selection of the remote sensing images. In this study, we used the TM images of Taiyuan city in 1990, 2000, and 2005.

2) The visual interpretation of the remote sensing images

२) Tho cunorricad rlaccifiration of romoto concina imarac $\lceil 51$

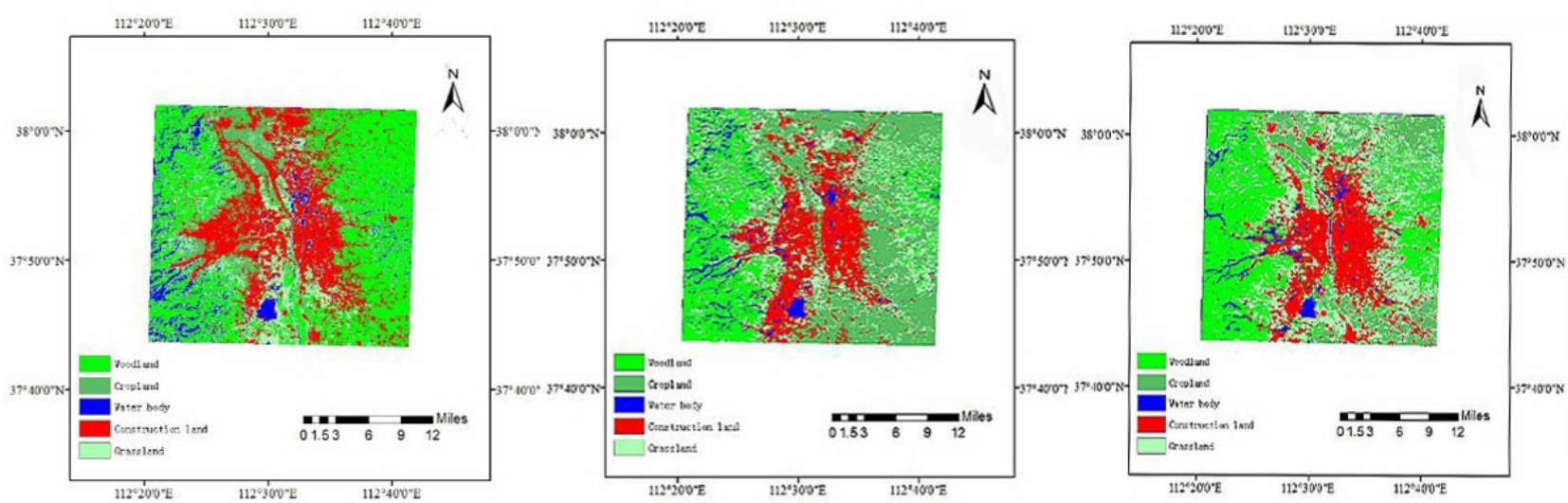

Fig2.Map of land use classification for 1990.2000 and2005

4) Using the ENVI tool to convert vector file, calculating area through the attribute table.

The data are different types of land area of the 1990, 2000 and 2005 in Taiyuan City. By importing the excel table, the area of each type of land is calculated, and the results are shown in the following table:

Table 2. Land use of different year

\begin{tabular}{cllllll}
\hline & \multicolumn{2}{c}{1990} & \multicolumn{2}{c}{2000} & \multicolumn{2}{c}{2005} \\
\hline & Area(km2 & Percentage & Area(km2) & Percentage & Area(km2) & Percentage \\
Woodland & 485.77 & $46 \%$ & 229.31 & $22 \%$ & 330.62 & $32 \%$ \\
Cropland & 142.74 & $14 \%$ & 361.69 & $35 \%$ & 156.87 & $15 \%$ \\
Water body & 72.39 & $7 \%$ & 45.41 & $4 \%$ & 36.59 & $3 \%$ \\
Construction & 176.19 & $17 \%$ & 205.75 & $20 \%$ & 224.99 & $22 \%$ \\
Grassland & 168.95 & $16 \%$ & 204.23 & $19 \%$ & 296.64 & $28 \%$ \\
\hline
\end{tabular}


As is shown in the chart above, these five different types of land area has taken on a quite obvious distinction in Taiyuan. Concretely speaking, it can be seen that woodland has reduced by $24 \%$ from 1990 to 2000 , and increased by $10 \%$ in next five years. While the area of cropland rise sharply by 21\% between 1995 and 2000 and then fell by 20\% between 2000 and 2005.The water body kept reducing during 1990 to 2005, while the construction land and the grassland area kept increasing between 1990 and 2000.

5) Using GIS to make the land use transition matrix of each period in Taiyuan city.

Land use transition matrix formula is

$$
\mathrm{A}_{\mathrm{ij}}=\left[\begin{array}{cccccc}
a 11 & a 12 & a 13 & \ldots & \ldots & a 1 n \\
a 21 & a 22 & a 23 & \ldots & \ldots & a 2 n \\
a 31 & a 32 & a 33 & \ldots & \ldots & a 3 n \\
\ldots & \ldots & \ldots & \ldots & \ldots & \ldots \\
\ldots & \ldots & \ldots & \ldots & \ldots & \ldots \\
a n 1 & a n 2 & a n 3 & \ldots & \ldots & a n n
\end{array}\right]
$$

Table3.1990-2000 Land use transition matrix

\begin{tabular}{ccccccc}
\hline $\begin{array}{c}1990-2000 \\
\left(\mathrm{~km}^{2}\right.\end{array}$ & Woodland & Cropland & $\begin{array}{c}\text { Water } \\
\text { body }\end{array}$ & $\begin{array}{c}\text { Construction } \\
\text { land }\end{array}$ & Grassland & Total \\
\hline Woodland & 116.0020 & 207.1031 & 6.1213 & 16.3201 & 100.5000 & 446.0377 \\
Cropland & 14.4135 & 45.4696 & 0.8586 & 18.5239 & 31.9884 & 111.2541 \\
Water body & 37.5738 & 2.0729 & 21.7711 & 5.7417 & 4.8769 & 72.0365 \\
Construction land & 6.8434 & 75.5281 & 8.4131 & 131.2000 & 30.0365 & 252.0210 \\
Grassland & 55.6626 & 31.8267 & 7.1779 & 34.7245 & 35.2417 & 164.6334 \\
Total & 230.4934 & 361.9972 & 44.3360 & 206.5126 & 202.6434 & 1045.9826 \\
\hline
\end{tabular}

Table4.2000-2005 Land use transition matrix

\begin{tabular}{ccccccc}
\hline $\begin{array}{c}2000-2005 \\
(\mathrm{~km})\end{array}$ & Woodland & Cropland & $\begin{array}{c}\text { Water } \\
\text { body }\end{array}$ & $\begin{array}{c}\text { Construction } \\
\text { land }\end{array}$ & Grassland & Total \\
\hline Woodland & 192.2000 & 4.5131 & 3.6051 & 4.1777 & 25.9870 & 230.4829 \\
Cropland & 34.4900 & 119.1000 & 2.1006 & 55.3575 & 151.0000 & 362.0481 \\
Water body & 18.0159 & 0.1965 & 18.2526 & 6.0503 & 1.5328 & 44.0481 \\
Construction land & 16.3810 & 7.8118 & 10.5033 & 138.1000 & 33.6801 & 206.4762 \\
Grassland & 69.6631 & 24.8762 & 1.7996 & 21.4869 & 84.8651 & 202.6908 \\
Total & 330.7500 & 156.4975 & 36.2612 & 225.1724 & 297.0650 & 1045.7461 \\
\hline
\end{tabular}

The row of the land use transition matrix form shows the change of land use types, the list shows the change direction, the shift direction of the land use types can be easily analyzed by the transfer matrix of land use.

Table5. 1990-2000 Shift direction

\begin{tabular}{cccc}
\hline Land type & New area $\left(\mathrm{km}^{2}\right)$ & Roll out area $\left(\mathrm{km}^{2}\right)$ & No change area $\left(\mathrm{km}^{2}\right)$ \\
\hline Woodland & 74.49 & 330.04 & 161.00 \\
Cropland & 286.53 & 65.78 & 75.47 \\
Water body & 22.56 & 50.27 & 21.77 \\
Construction land & 151.31 & 119.82 & 56.20 \\
Grassland & 196.40 & 165.39 & 31.83 \\
\hline
\end{tabular}


Table6. 2000-2005 Shift direction

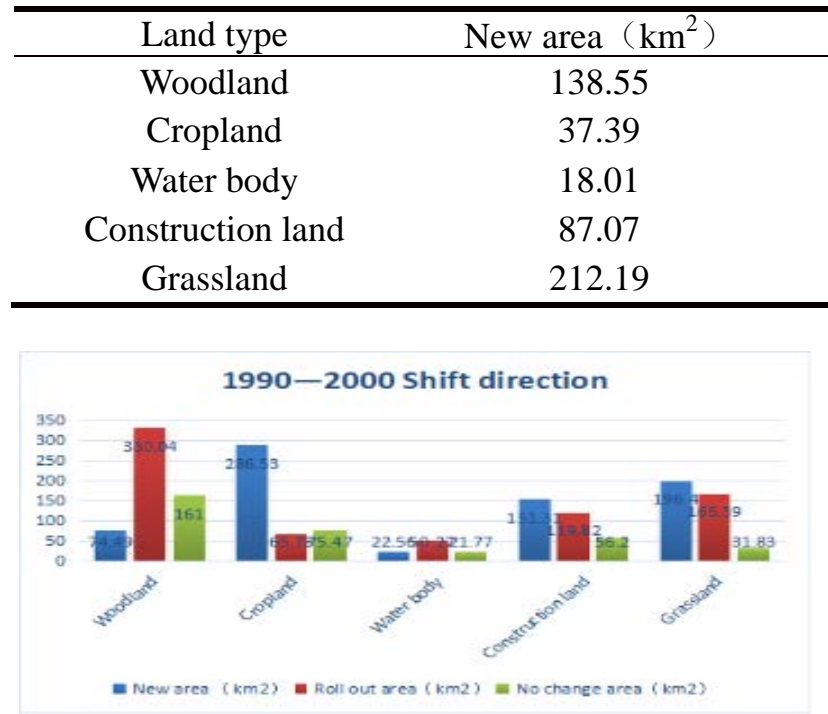

Fig3. 1990-2000 Shift direction

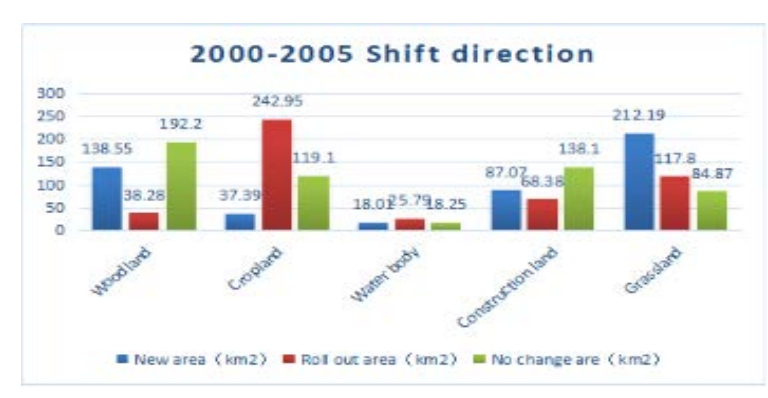

Fig4. 2000-2005 Shift direction

We analyze quantitatively the 15 years of land use change direction from 1990 to 2005 in the help of land use transfer matrix. It provides the basis for the future research about the land use change. As is shown in the shift direction between 1990 and 2000 (Figure3),330.04 ha of woodland were turned into other type land. We can see from the Chart3, 207.10 ha and 100.5 ha of the woodland were converted to cropland and grassland respectively. During the same time, 18.52 ha and 34.72 ha of construction land came from the cropland and grassland. According to the shift direction between 2000 and 2005(Figure 4), the roll out area of cropland has the maximum shift. There exists 55.35 ha and 151 ha of cropland transformed into construction land and grassland, respectively. The new area of grassland and construction land mainly came from the woodland and the cropland.

6) Analysis of change speed of the land use types in Taiyuan city.

The change speed of each land type can be calculated by using the dynamic model of the single land use. Dynamic degree of land use can not only quantitatively study the speed of land use change, but also predict the trend of future land use change and its development direction.

The dynamic degree of single land use is the main research of the problem of the rate of the change of the land use types in the study area (beginning: $t 1$, end: $t 2$ ). Its mathematical expression formula is:

$$
\mathrm{K}_{\mathrm{j}}=\frac{\left(L A_{(j, t 2)}-L A_{(j, t 1)}\right)}{L A_{(j, t 1)}} \times \frac{1}{t 2-t 1} \times 100
$$

where $\mathrm{K}_{\mathrm{j}}$ is the dynamic degree of the land use type $\mathrm{j}$ in the study area during the study period (from the initial time to the final time t2-t1), which is showing the annual change rate of the land use type.

Table.7 Land use dynamic degree of 1990-2005

\begin{tabular}{ccccc}
\hline Land use types & $\begin{array}{c}\text { The area of } 1990 \\
\left(\mathrm{~m}^{2}\right)\end{array}$ & $\begin{array}{c}\text { The area of } \\
2005\left(\mathrm{~m}^{2}\right)\end{array}$ & $\begin{array}{c}\text { Area change } \\
\left(\mathrm{m}^{2}\right)\end{array}$ & $\begin{array}{c}\text { Single land use } \\
\text { dynamic degree }\end{array}$ \\
\hline Woodland & 485.77 & 330.62 & -155.15 & -2.129 \\
Cropland & 142.74 & 156.87 & 14.13 & 0.650 \\
Water areas & 72.39 & 36.59 & -35.79 & -3.296 \\
Construction land & 176.19 & 224.99 & 47.79 & 1.808 \\
Grassland & 168.95 & 296.64 & 127.69 & 5.038 \\
\hline
\end{tabular}

As we can see from the chart, each land has their own dynamic degree. We know that the number of dynamic degree shows the degree of change of each land type. For example, the dynamic 
degree of grassland is the maximum, which means that the grassland's change was the fastest during the fifteen years. The local people not only take efforts to the expansion of construction land, but also pay more attention to the protection of grassland and cropland, which will be conducive to the healthy and reasonable development of the city in the future.

\section{Summary and Conclusion}

According to the chart, the area of woodland decreased significantly, while the area of crop land increased obviously from 1990 to 2000. The area of crop land decreased while the area of woodland increased from 2000 to2005 on account of the policy of "returning farmland to forest" by government in 1999. It's visible that the land use is related to the decision-making of the government.

Population plays a key role for the development of a city, which needs abundant resources that come from the human beings' labor production. With the increase of construction land, it was directly reflected that the urban population growth and the level improving of urbanization after 1990. The continued increase of grassland area owe to people' paying attention for green and the improvement of living standards. Water body continues to reduce, reflecting the tendency of urban climate warming.

In summary, it is highly necessary to pay attention to the harmonious development of man and nature in the process of urbanization rather than only build a better home for ourselves. As a member of the nature, the human beings should try our best to take the initiative to make full use of resources for the development of the entire community. At the same time, we should not only develop the city's own economy, but also pay attention to the quality of the population and the quality's improvement. Human beings should pay more attention to the rational use of farmland, so that it can be used effectively and the unused land can be developed rationally. It's essential to adjust the structure of land use, optimize the environment, increase the green area, and improve the urban infrastructure and the quality of society service for the whole city’s future development.

\section{Acknowledgements}

This research work was supported by the Natural Science Foundation of Beijing [Grant No.8142009].

\section{References}

[1] Yong Liua, Jinchang Li: An ecosystem service valuation of land use change in Taiyuan City, China. Ecological Modelling 225 (2012) 127-132.

[2] Jieying Xiao,Yanjun Shen:Evaluating urban expansion and land use change in Shijia zhuang, China, by using GIS and remote sensing, Landscape and Urban Planning 75 (2006) 69-80.

[3] Wu Zhu, Qin Zhang, Recent ground deformation of Taiyuan basin (China) investigated with C-, L-, and X-bands SAR images, Journal of Geodynamics 70 (2013) 28-35.

[4] Qifeng Tang, Qing Xu, Fucun Zhang. Geochemistry of iodine-rich groundwater in the Taiyuan Basin of central Shanxi Province, North China. Journal of Geochemical Exploration 135 (2013) 117-123.

[5] SU Changhong, FUBojie.Land Use Change and Anthropogenic Driving Forces:A Case Study in Yanhe River Basin. Chin.Geogra. Sci. 2011 21(5) 587-599. 